\title{
BRUNO dos Reis, HETERÔNIMO DE Virgílio de LEMOS: MÚSICA E SUBVERSÃO EM TIMBRES METAPOÉTICOS ${ }^{1}$
}

LUCIANA BRANDÃo LEAL*

\section{Resumo}

Este artigo apresenta leituras e análises de poemas assinados por Bruno dos Reis, heterônimo do poeta moçambicano Virgílio de Lemos. Bruno dos Reis é o "poeta-cronista" que assume o lugar de fundador da poesia virgiliana e "máscara que confessa o sujeito", apresentando textos críticos e literários fundados na metalinguagem, como os editoriais previstos para Revista Msaho.

Palavras-chave: Bruno dos Reis. Heteronímia. Poesia moçambicana. Subversão.

Virgílio de Lemos e seus heterônimos: o estilhaçamento do "eu" que escreve - outros trânsitos

Virgílio de Lemos criou seus três principais heterônimos que são, essencialmente, diferentes e concretizam propostas de criação poética que se distanciam da escrita ortônima. Couto (1999, p. 16), a propósito, reconhece essa peculiaridade da poesia de Lemos, quando afirma: "dividido enquanto ser, a estratégia de sua escrita não podia ser outra senão a dispersão - Virgílio se reparte em heterônimos”. Considera-se que, na criação virgiliana, a heteronímia se configura como um importante

Doutora em Letras - Literaturas de Língua Portuguesa. Professora na Universidade Federal de Viçosa/UFV, Viçosa, Minas Gerais, Brasil.

E-mail: luciana_brandao@hotmail.com Orcid iD: https://orcid.org/0000-0003-1534-9726

1 Este artigo retoma, em suas considerações iniciais, parte da discussão exposta em Máscara e performance - literaturas lusófonas em diálogo: o desdobramento em heterônimos na lírica de Virgílio de Lemos, leitor de Fernando Pessoa, publicado na Revista Navegações, v. 12, n. 2, 2019. https://doi.org/10.15448/1983-4276.2019.2.34064. O texto citado apresenta análise do processo heteronímico na escrita do poeta Virgílio de Lemos. Discute-se, especificamente, a concepção poética dos três principais heterônimos virgilianos: Lee-Li Yang, Duarte Galvão e Bruno dos Reis. Portanto, o presente texto aprofunda a discussão sobre a escrita do heterônimo Bruno dos Reis, heterônimo "musical" e "subversivo" de Virgílio de Lemos. 
trânsito literário, na medida em que a performance do autor cria outras personalidades reais (embora sejam autores de papel), na tentativa de expressão de si próprio e de evocar a identidade fragmentada que se mostra em sua escrita que, por vezes, pode ser entendida como alusão à nação moçambicana.

Investigar a obra poética de Virgílio de Lemos, ortônimo, e de seus heterônimos possibilita compreender os esforços desse poeta contra o "império da razão" então vigente, assumindo várias feições e diversas identidades, levando a extremo as influências das vanguardas e rompendo, definitivamente, com os padrões da poesia colonial. A sua poesia traz as marcas históricas do povo moçambicano e suas diásporas; transitando pelas ilhas moçambicanas - Muhípiti, Ibo, Quirimbas, Mutanda, Mutumwe e Ouamisi -, ele revisita autores clássicos e contemporâneos, demonstrando empenho em combater o isolacionismo da literatura de Moçambique.

$\mathrm{O}$ trânsito pelos heterônimos alude à despersonalização do poeta, que se desdobra em outros, levando a cabo o fingimento poético. No processo de criação virgiliana, o sujeito poético demonstra sentir-se "um estrangeiro para si mesmo", partindo-se em vários "cacos" que expõem o estilhaçamento da imagem interior. Em um movimento aparentemente contrário, o eu lírico procura afirmar sua identidade múltipla por meio do corpo da poesia.

O trânsito da palavra sobre o mar é um movimento vertiginoso e surreal, mergulho no azul infinito da imaginação criadora. $\mathrm{O}$ mar e o azul dão a tônica e o movimento da lírica de Lee-Li Yang, poeta sensível, apaixonada, vibrante. Mulher erótica / erotizada. Lee-Li Yang rebela-se contra os padrões que cerceiam a feminilidade e a voz da mulher em um espaço colonial e machista, resiste à violência do sistema patriarcal e não se curva a ele; ao contrário, subverte-o, com seus poemas eróticos.

Lee-Li Yang, apaixonada por Duarte Galvão, escreve-lhe cartaspoemas de desejo e falta, clama sua presença. Duarte Galvão, a voz revolucionária que levou o poeta Virgílio à prisão, louvou a cidade, a urbe 
e a mulher, com suas formas sinuosas trazidas pela memória, tendo sido o arauto de $M s a h o^{2}$, empreendimento revolucionário que ainda hoje guarda a sua modernidade. O primeiro e único número de Msaho evidencia o pensamento "DADA" pela arte, pelas cores, pelas opções estéticas e poéticas. Duarte Galvão talvez seja o heterônimo mais conhecido de Virgílio de Lemos, sendo ao menos o que tem maior produção poética. Em muitos momentos, a poesia desse ortônimo se confunde com a do heterônimo. Em outros, ambos assinam os poemas. Há fingimento poético, à luz do mestre: Fernando Pessoa. Há radicalização do fingimento: Duarte Galvão depõe a máscara de Bruno dos Reis.

Se Duarte Galvão apresenta em seus poemas uma feição contestatória e assume a identidade de Msaho, cabe ao heterônimo Bruno dos Reis assinar cinco dos seis editorais previstos para as futuras edições da revista, que não foram publicadas. Nas poesias de Duarte Galvão, enunciam-se e encenam-se os preceitos que Bruno dos Reis anuncia, criticamente, nos editoriais já citados. Em suma, a ideia era difundir a "literatura embrionária” (REIS apud LEMOS, 2009, p. 605) - sendo ela a poesia de várias regiões de Moçambique e do exterior - da subjetividade e da diáspora.

2 Um exemplar digitalizado da revista Msaho (1952) foi apresentado nos anexos da tese Virgílio de Lemos: poesia em trânsito (LEAL, 2018). Ter acesso a esse exemplar foi uma conquista importante do período de pesquisas em Lisboa, pois apresenta ao público leitor a revista em sua concepção inicial e única. A cópia foi feita a partir do original, em papel amarelo, como os papéis dos primeiros registros dos poemas verticais de Noémia de Sousa. Como dado informativo: Há duas cópias da revista Msaho (1952) disponíveis na Biblioteca Nacional de Lisboa, Calouste Gulbenkian, mas não podem ser manuseadas pelos leitores, pelo fato de serem exemplares raríssimos; entretanto, o acesso foi permitido após confirmado o vínculo de pesquisadora visitante da Universidade de Lisboa. Explicitei a importância de trazer ao Brasil uma cópia digitalizada de Msaho, dado fundamental para o meu trabalho, uma vez que ela representa um marco na concepção poética de Virgílio de Lemos e do projeto literário de Moçambique. Gentilmente, o bibliotecário responsável atendeu aos meus reiterados apelos, fez uma cópia digitalizada da revista e salvou em pendrive, já que eu não poderia, em hipótese alguma, retirá-la da biblioteca para levá-la a uma gráfica (com digitalização). Esse empenho tornou possível divulgar a revista Msaho no Brasil, em sua imagem original, trazendo ao público a modernidade gráfica e a proposta vanguardista que esse empreendimento literário representou (e representa) no cenário da literatura moçambicana do século XX. 
Curiosamente, é Bruno dos Reis, o poeta-cronista, que assume o lugar fundador da poesia heteronímica de Virgílio de Lemos, "máscara que confessa o sujeito", na medida em que apresenta reflexões e análises críticas sobre o campo da representação. O lugar de fala de Bruno dos Reis é metafísico, universal; enquanto Lee-Li Yang assume a voz poética do mar e Duarte Galvão canta a cidade Lourenço Marques, os espaços social e político moçambicano.

Bruno dos Reis, poeta-crítico, tem passagens elucidativas, com reflexões profundas sobre a cultura, os trânsitos e as aspirações de poetas que se pretendiam revolucionários. Escreve os editoriais para os futuros números da revista Msaho: "movimento-música”. Deposto de sua máscara, de sua persona, Reis se torna o "cronista" das vanguardas virgilianas. Vanguardas múltiplas, como múltiplos são os trânsitos do poeta moçambicano.

Bruno dos Reis, por seu turno, escreveu poucos poemas e se manifestou, mais frequentemente, como cronista. Lemos justifica esse fato: "Vindo da poeticidade, é, entretanto, o heterónimo mais próximo de Ricardo Reis e também da crítica da história e da filosofia. Seus textos foram publicados, sobretudo, entre 1952 e 1953, no jornal Notícias da Tarde" (LEMOS, 1999, p. 147).

Foi o heterônimo Bruno dos Reis quem definiu: "a heteronímia é em si uma forma de vertigem” (REIS in LEMOS, 2009, p. 603). Essa percepção permite a discussão da heteronímia de Virgílio de Lemos e dos trânsitos desse poeta por sua constelação de vozes que reiteram sua errância e possibilitam a criação de um mundo poético rico em vozes e intertextualidade.

Bruno dos Reis, o Heterônimo de Virgílio de Lemos: A PALAVRA MUSICAL E SUBVERSIVA

Lemos (1999, p. 142) explica quem foi Bruno dos Reis salientando que esse heterônimo escreveu várias crônicas e textos críticos: "Um 
heterónimo meio filósofo, cerebral; alguns dos seus textos terão sido publicados entre 1952-1953 no jornal Notícias da Tarde”. Bruno dos Reis escreveu algumas poesias que estão publicadas em antologias mais recentes, como Jogos de Prazer e A dimensão do desejo.

Os anexos da antologia Jogos de Prazer trazem os editoriais, até então inéditos, assinados por Virgílio de Lemos e pelo seu heterônimo Bruno dos Reis, fato já citado na introdução deste artigo. Esses textos foram escritos para serem publicados em números da revista Msaho que não chegaram a ser lançados, porque a censura proibiu a circulação do seu caderno literário, mas também pela falta de recursos para a sua impressão e distribuição. Além de considerar o lugar do poeta nos cenários político e social do país, os textos tratam dos parâmetros que norteariam a nova poesia moçambicana, singular e universal. Sobre isso, Lemos (2009, p. 604) escreve: "A poesia em Moçambique será uma poesia liberta de todas as amarras [...] Ela não poderá ser apenas uma poesia de militância e protesto".

Quando Lemos afirma que Bruno dos Reis é seu heterônimo mais cerebral, refere-se ao fato de que esse propunha análises profundas sobre os contextos social e histórico dos espaços colonizados. Ao refletir sobre a Segunda Guerra Mundial e seus reflexos diretos no processo das colônias, por exemplo, Bruno dos Reis posiciona-se nestes termos:

Devemos reconhecer que a estratégia em que se inscreve a reconstrução dos países atingidos pela guerra e os que a eles estão ligados, tais as suas colónias [...] E que apesar das resistências locais e vozes reclamando a emancipação, esse processo continua a ser lento, que se trate d’África, Ásia ou América Latina. (LEMOS, 2009, p. 606)

Bruno dos Reis (LEMOS, 2009) prossegue sua análise da repressão "a nível continental" afirmando que apenas uma "explosão de sangue" poderia libertar as colônias de um "beco sem saída”, mostrando-se em consonância com o pensamento de Fanon (2005). 
Para ele, o homem colonizado está cerceado de liberdade de expressão, amordaçado. Nesse contexto de violência extrema, a poesia articula e expressa o "mal-estar", na medida em que denuncia as dicotomias raciais, culturais e sociais. Contra o poder colonial e a repressão, está "a poesia à escala do mundo, mas particularmente a poesia da negritude" (REIS in LEMOS, 2009, p. 607). Bruno dos Reis também retoma ícones como Aimé Césaire, Léon Damas e Léopold Senghor, além dos poetas negros norte-americanos, empenhados na luta pela dignidade do homem negro.

Os textos assinados por Bruno dos Reis reiteram o desejo latente de criação de uma nova estética para a poesia moçambicana, incorporando à tradição a novidade; a palavra como subversão, a euforia da linguagem, a voz musical em busca de novas influências para as letras moçambicanas:
A palavra é subversão
ou morte!
Palavra. Voz musical
do que respiro
sussurro
da minha solidão!
No que me escapa
me abandono.
Me transcendo.
Não serei mais que
viagem
(REIS in LEMOS, 2009, p. 98)

As palavras desse heterônimo sugerem "abrir as janelas dentro e fora deste Moçambique [...] Abrir as janelas de par em par. Bater as portas malcriadamente" (REIS in LEMOS, 2009, p. 606). Os versos do poema "Fecho e Abertura", assinado por Bruno dos Reis, transcrito a seguir, retomam os parâmetros aqui apresentados: 


\section{FECHO E ABERTURA}

No amor há sempre dois por vezes três

e no entanto somos mais circunstancialmente

Reinaldo e Holderlin Sá Carneiro e Rilke

O’Neil e Cesariny Álvaro Campos e Withman

Ricardo Reis Caeiro e Pessoa

no alado olho do piscar d'olhos

quebra cabeça do borboletejar da poesia

voz de msaho - reabilitação de um tempo por desvendar!

(REIS in LEMOS, 2009, p. 38)

Nesse movimento de abertura para o "outro", a literatura e, especialmente, a poesia teriam uma função essencial. Nos espaços coloniais portugueses, a poesia escrita em língua portuguesa poderia ser uma nova proposta de mudança. $\mathrm{O}$ heterônimo virgiliano caracteriza o espaço da literatura da seguinte maneira:

Poesia da vida quotidiana, poesia neo-realista, poesia sensacionalista, dadaísta, surrealista. Poesia que vem da oralidade abraçada à música. Poesia dos trovadores. Poesia da revolta. Sejamos sobretudo poesia. Diálogo com o outro, sendo para começar diálogo com o outro dentro de nós. À maneira de Shakeaspeare, Camões, T. S. Eliot, Mário de Andrade, Oswald, Drummond de Andrade. (REIS, in LEMOS, 2009, p. 608).

Bruno dos Reis trata a poesia como "força motriz" para mudança social; não aquela poesia que cultua o exotismo ou que está relegada somente ao plano decorativo, mas a "poesia de revolta", emancipatória, que possa contribuir, efetivamente, para a transformação social e do próprio homem, "dignificando a imagem de um país e de uma língua no mundo” (REIS in LEMOS, 2009, p. 608).

Nota-se uma reflexão cuidadosa sobre a função da poesia e da literatura, bem como do lugar do poeta no espaço moçambicano: "a voz 
de quem reclama igualdade de direitos, fraternidade e amor" (REIS in LEMOS, 2009, p. 610).

Sobre a revista Msaho, Bruno dos Reis escreve: "Msaho será, sem pretensões, a busca de uma nova luz. Uma outra palavra. Sendo poesia de solidão e desespero, será uma poesia de revolta, de protesto, mas de ironia e de humor" (REIS in LEMOS, 2009, p. 606).

Assim como os múltiplos significados atribuídos à palavra Msaho: "canto", "espetáculo musical de várias orquestras de timbila" e "dança orquestral acompanhada de canto", e as várias propostas da revista idealizada por Virgílio de Lemos, a poesia de Bruno dos Reis traz influências da música e do canto, "uma nova luz", capaz de revitalizar e reinventar a palavra poética. Nos dois exemplos transcritos a seguir, temos a mesma tônica dessa evocação musical:

\section{ENTRE A PALAVRA E A POESIA}

De trilos imperfeitos incompletos fragmentos musicais ilimites e limites infernais sede de desejo e lira d'impaciências no jogo perverso e nu entre a palavra e a poesia.

(REIS in LEMOS, 2009, p. 105)

No poema "Entre a palavra e a poesia", o que se vê é a euforia da linguagem e a liberdade de se manipular o fragmentado verbo. Retomando o conceito de palavra como subversão, nota-se, também, a intenção de se resgatar a palavra musical, oral, "sede de desejo e lira" (o eu poético sedento por resgatar a palavra oralizada e lírica ou mesmo a sede do desejo, no sentido de casa, espaço e lugar), o que significa subverter a rigidez e os 
limites estabelecidos pela forma de concepção poética, buscando o "jogo perverso e nu / entre a palavra e a poesia":

\author{
A "Sonata incompleta" de \\ Schubert \\ não antes das sonatas e \\ nocturnos \\ de Haydn e Bach! \\ No movimento musical da beleza se dilui \\ ampla voz \\ do silêncio! \\ (REIS in LEMOS, 2009, p. 100)
}

Bruno dos Reis exalta grandes compositores clássicos, trazendoos à cena enunciativa desse poema sem título. Os concertos clássicos se baseiam, fundamentalmente, na clareza e no equilíbrio da estrutura formal e da linguagem musical. Nesse poema, faz-se referência, inicialmente, a Franz Peter Schubert, compositor austríaco de estilo marcante, inovador e poético, autor de inúmeras óperas e sinfonias, incluindo a famosa "Sinfonia Incompleta” (Sinfonia No 8). Refere-se, também, a Franz Joseph Haydn, que personifica o chamado "Classicismo Vienense"; além do alemão Johan Sebastian Bach, um dos maiores expoentes da música clássica. Em outro poema, Bruno dos Reis cita novamente Bach:

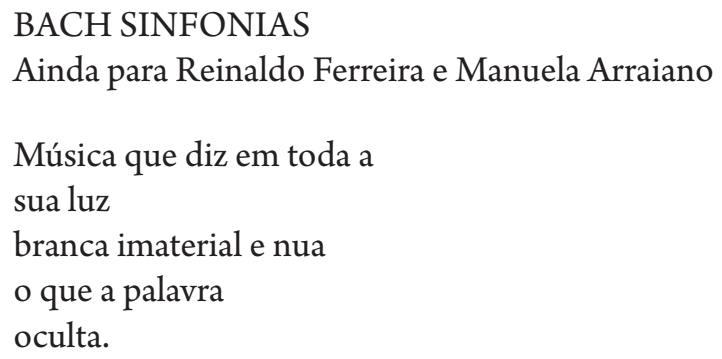

Música da alma que seduz e espiritual enobrece corpo e gesto. 
Sons que se apagam da memória

e reaparecem outros

sons mais soltos e livres

violência diluída

no teu sangue.

Luz!

(REIS in LEMOS, 2009, p. 101)

Mais uma vez, a clareza musical da sinfonia clássica é enaltecida. Vocábulos e metáforas são responsáveis por reforçar essa ideia: “”luz branca", "sons mais soltos e livres", "luz!”. Esse poema acerca-se da estética simbolista, tanto pela evocação musical quanto pela presença das sinestesias, que aproximam os campos sensoriais diferentes: "música branca, imaterial e nua”. A voz, em performance, extrapola os limites semânticos e se manifesta na totalidade do espaço textual como "corpo e gesto”. A voz é, também, o aspecto socializador, na medida em que a palavra cantada (entoada poeticamente) é espaço da liberdade: "sons mais soltos e livres / violência diluída / no teu sangue”.

É, também, Bruno dos Reis que, em texto crítico, estabelece as relações entre a nova poesia moçambicana, as vanguardas e os movimentos artísticos provenientes de outros espaços. As palavras do heterônimo virgiliano confirmam os novos parâmetros e opções estéticas para produção literária: "Abertos à poesia de todos os simbolismos e surrealismos. Aos concretismos e modernismos contemporâneos. Sejamos d’Aqui sendo do outro lado, sendo regionais, sejamos cosmopolitas, universalistas à maneira de Withman e F. Pessoa” (REIS in LEMOS, 2009, p. 606). Quando escreve o poema "Quinta carta de Bruno Lee a Lee-Li Yang", Bruno dos Reis suscita as influências de movimentos artísticos externos, como o Surrealismo e o Dadaísmo, além de trazer referências importantes, como às poetisas Cecília Meireles, Glória de Sant’anna e Marianne Moore:

\section{QUINTA CARTA DE BRUNO LEE A LEE-LI YANG}

Repensar-te divina Ariel 
mas sem esquecer

Lee-Li e outros Mestres,

Cecília, Glória e

Marianne Moore - o que seria

sacrilégio.

E tu Lee-Li, meio Dada e

Surrealista, tu sendo festa

e orgia de um outro Carnaval,

a "desmedida" e fora-

da-lei matricial

festa da poesia.

$[\ldots]$

(LEMOS, A dimensão do desejo, p. 36)

Em outra carta-poema endereçada ao heterônimo feminino de Virgílio de Lemos, Bruno dos Reis caracteriza a voz lírica e "a magia dos versos” de Lee-Li Yang: "voz órfica”, “voz da nudez”:

NOVA CARTA PARA LEE-LI

Grito que não deixa cicatrizes!

O que acorda no teu espaço é a tua voz órfica,

Voz da nudez! [...]

(LEMOS, A dimensão do desejo, p. 37)

Para Bruno dos Reis, Duarte Galvão escreveu seu poema "Heterónimo", cuja interpretação é um grande desafio para os leitores. O “jogo do texto" - nos parâmetros propostos por Iser - está, aqui, encenado; evidenciando, sobremaneira, a singularidade poética de Virgílio de Lemos. Considera-se a proposta de Iser (2002, p. 107): "Assim o texto é composto por um mundo que ainda há de ser identificado e que é esboçado de modo a incitar o leitor a imaginá-lo e, por fim, interpretá-lo". No "jogo textual” proposto por Virgílio de Lemos, os heterônimos dialogam entre si, escrevem e trocam cartas uns com os outros, respondem cartas; mas como entender o fato de um heterônimo sugerir a "morte" do outro? O poema 
"Heterônimo" suscita, nos leitores de Virgílio de Lemos, a consciência de participarem do jogo lúdico da linguagem.

É Duarte Galvão quem assume a enunciação do poema "Heterónimo" e, reflexivamente, declara: "Rasguei a máscara de Bruno dos Reis". Reafirmando o processo de interlocução, tem-se um "eu" que enuncia para um "tu”, característica comum na lírica virgiliana, que pode ser observada em vários outros poemas já citados. No poema "Heterónimo", entretanto, as marcas do discurso sugerem, em alguns momentos, que "eu" e "tu” se confundem. Desde o título, é curiosa a opção pelo singular, "heterônimo" e não "heterônimos", uma vez que se trata de um diálogo entre duas "personas" virgilianas. Vejamos:

\section{Heterónimo}

Nesta tragédia de existir

Vou-me conhecendo a cada passo.

Rasguei a máscara de Bruno dos Reis

E chorei lágrimas de cansaço

De ter sido incoerente com o que sou;

Nota-se, no fragmento destacado, a busca pela identidade (de si e do outro?).

Rasguei mesmo todos os poemas liberais

Que o Bruno dos Reis me ditou;

E hoje que é sexta-feira maior

$\mathrm{E}$ fez anos que Cristo morreu

Acentuou-se em mim a razão interior

Que me fazia ateu; [...

Reafirmando o fingimento poético e o jogo do texto, o eu lírico sugere que os seus próprios poemas foram ditados por Bruno dos Reis; entretanto, a melancolia o afasta de todas as crenças. A lucidez, advinda da melancolia, o faz reconhecer o "absurdo dos laços e dos seres" (KRISTEVA, 1987, p. 12) - “acentuou-se em mim a razão interior": 
Fiz logo exame de consciência

E obriguei-me à penitência

De me tornar Eu mesmo;

Não importa o abismo que nasceu

Entre mim, Bruno e o mundo;

Importa, sim, haver uma razão

Que torna o abismo profundo.

Mas que parto infeliz? Que sensação

De ferros penetrando em mim...

Sinto-me perdiz feita presa

Após a ressurreição.

Tornei-me finalmente Eu mesmo!

Porém, que atroz confusão:

Vivendo comigo a esmo

Uma esmagadora certeza

Grita-me: Bruno dos Reis, tu mesmo!

Eu mesmo, irremediavelmente, Bruno!

(GALVÃO in LEMOS, 2010, p. 273)

Esse poema, assinado por Duarte Galvão, encena a complexidade da heteronímia de Virgílio de Lemos, que promove a teatralização da escrita literária. A sua dramatização é tão radical que seus "avatares" literários se encontram como fantasmas e parceiros da escrita desse "eu", que é múltiplo. Tem-se uma aventura existencial e ontológica: "Bruno dos Reis, tu mesmo! / Eu mesmo, irremediavelmente, Bruno!”; o jogo do texto traz a simulação de múltiplos sentidos dados ao "eu" que enuncia (Duarte Galvão, Bruno dos Reis ou o ortônimo Virgílio de Lemos?), além da própria simulação de sentidos evidente no título do poema: "Heterônimo". A heteronímia em Virgílio de Lemos pode ser caracterizada conforme afirma Duarte (2010, on-line), em estudo sobre a obra de Fernando Pessoa: "Essa valorização da máscara, essa confissão de fingimento, essa consideração de que a normalidade está no uso da máscara fazem-nos 
suspeitar de que também os heterônimos seriam máscaras, mais do que soluções”. A solução proposta por Duarte Galvão, "retirar a máscara de Bruno dos Reis", evidencia a consciência de uma época em que a tônica são o fingimento e a representação.

A máscara é a metáfora da performance e da possibilidade de "outrarse" - ou seja: de tomar posse da personagem para nela atuar -, o que remete a tempos imemoriais. No teatro grego, por exemplo, as máscaras estabelecem relações com ritos primitivos, tornando-se objetos sagrados. É por intermédio delas que ressoa a voz do ator, o poder do verbo e da ação. Segundo Lopes (2010, p. 32), “despojado das suas feições mais expressivas, de seu potencial de comunicação: rosto e voz - o corpo do ator vai descobrindo recursos de expressão nunca experimentados, tornandose aos poucos um rosto visto em close”. As máscaras do teatro grego também serviam para prender a atenção dos expectadores, expressando a essência do drama, perpetuando o clima mítico da tragédia e o grotesco da comédia. No decorrer do espetáculo, os atores trocavam de máscaras diversas vezes, porque cada uma representava determinada emoção ou estado da personagem. Em suma, a máscara teatral viva em cena é, em si, a própria essência do teatro. Ela é um arquétipo que leva o ator à representação e se fundamenta na despersonalização de quem a incorpora para simbolizar a pluralidade do ser humano, que pode assumir várias identidades. Como em um grande espetáculo teatral, o desdobramento de personalidades é uma característica inerente ao homem, que assume várias "personas” em sua vida cotidiana, desempenhando vários papéis no "palco do mundo".

Um poema de Álvaro de Campos, transcrito a seguir, também remete à metáfora da "máscara”, do despir-se da máscara ficcional. Vejamos:

Depus a máscara e vi-me ao espelho. -

Era a criança que há quantos anos.

Não tinha mudado nada...

É essa a vantagem de saber tirar a máscara.

É-se sempre a criança, 
O passado que foi

A criança.

Depus a máscara, e tornei a pô-la.

Assim é melhor,

Assim sem a máscara.

E volto à normalidade como a um términus de linha.

(CAMPOS, 1993, p. 61)

Nesses versos e em outros do já citado poema "Tabacaria” (CAMPOS, 2010, p. 397), faz-se referência à mesma metáfora: "Quando quis tirar a máscara, / Estava pegada à cara". Nos dois exemplos citados, ambos do heterônimo pessoano Álvaro de Campos, vê-se a analogia à teatralização que Virgílio de Lemos explicita em seu poema "Heterônimo". Os versos "Depus a máscara, e tornei a pô-la", "Quando quis tirar a máscara / Estava pegada à cara” e "Rasguei a máscara de Bruno dos Reis" reiteram o movimento de personalização e despersonalização no que tange à questão heteronímica. No primeiro caso, a máscara é retirada para retomar a infância; no segundo, é impossível despir-se das máscaras do fingimento. Nesse poema virgiliano, o heterônimo Duarte Galvão responsabiliza-se por retirar a máscara de Bruno dos Reis. O movimento de depor e repor as máscaras resgata movimentos teatrais, performativos e figurativos dos palcos, o que torna excepcional a obra de Virgílio de Lemos.

Analisando-se as várias vozes presentes no poema "Heterônimo" e na lírica virgiliana, constata-se que o jogo heteronímico está na estrutura da poesia de Virgílio de Lemos e que o desdobramento heteronímico marca um traço da personalidade desse poeta moçambicano. Como ele mesmo afirma em entrevista, o fenômeno do desdobramento em outras "personas" pode ser explicado pela teoria lacaniana sobre o "descentramento do sujeito". A multiplicação das personalidades e a criação de autores de papel são a essência da subjetividade de um poeta em trânsito pelos recursos estéticos, pelos espaços e temas que ecoam em suas letras.

Considerando-se todos os aspectos discutidos, não há dúvidas do quanto o poeta Virgílio de Lemos foi vanguardista no contexto da 
poesia moçambicana. Abrir as letras moçambicanas a outras vozes, a outras influências era o desejo constantemente reiterado pelo escritor, neste empenho Virgílio de Lemos - por sua escrita ortônima - e as de seus heterônimos estabelecem com as vanguardas europeias, com as vanguardas latino-americanas e com outros movimentos artísticos que revolucionaram as Artes no século XX.

BRUNO dos ReIS, VIRGílio de LEMOS' HETERONYM: MUSIC AND SUBVERSION IN METAPOETIC TIMBRES

\section{AbSTRACT}

This article presents readings and analyzses of poems signed by Bruno dos Reis, heteronym of the Mozambican poet Virgílio de Lemos. Bruno dos Reis is the "poet- chroniclerst", who takes the place of founder of Virgilian poetry, "a mask that confesses the subject", presenting critical and literary texts based on metalanguage, such as the editorials planned for Revista Msaho Magazine.

KEYwORDs: Bruno dos Reis. Heteronym. Mozambican poetry. Subversion.

BRUNO dos ReIS, HeteróNIMO DE ViRgílio de LeMOS: MÚSICA Y SUBVERSIÓN EN TIMBRES METAPOÉTICOS

\section{RESUMEN}

Este artículo presenta lecturas y análisis de poemas firmados por Bruno dos Reis, heterónimo del poeta mozambiqueño Virgílio de Lemos. Bruno dos Reis es el "poeta-cronista" que ocupa el lugar de fundador de la poesía virgiliana y "máscara que confiesa el sujeto", presentando textos críticos y literarios basados en el metalenguaje, como los editoriales previstos para la Revista Msaho.

Palabras Clave: Bruno dos Reis. Heteronimia. Poesía mozambiqueña. Subversión.

\section{REFERÊNCIAS}

BOSI, Alfredo. O ser e o tempo da poesia. São Paulo: Cultrix, Ed. da Universidade de São Paulo, 1977. 
CÂNDIDO, Antonio. O direito à literatura. In: CÂNDIDO, Antonio. Vários escritos. Rio de Janeiro: Duas Cidades, 2004.

CHAVES, Rita. Angola e Moçambique: experiência colonial e territórios literários. Cotia: Ateliê Editorial, 2005.

CHAVES, Rita; MACEDO, Tânia (org.). Marcas da diferença: as literaturas africanas de língua portuguesa. São Paulo: Alameda, 2006.

COUTO, Mia. O pouco do tudo. In: LEMOS, Virgílio de (org.). Eroticus moçambicanus: breve antologia da poesia escrita em Moçambique (1944/1963). Rio de Janeiro: Nova Fronteira,1999. p. 15-17.

DUARTE, Lélia Parreira. Heteronímia e ironia em Fernando Pessoa. 2010. Disponível em: http://www.leliaparreira.com.br/images/ensaios/heteronimia. pdf Acesso em: 10 nov. 2017.

FANON, Frantz. Os condenados da terra. Tradução de Enilce Albergaria Rocha e Lucy Magalhães. Juiz de Fora: Ed. UFJF, 2005.

FONSECA, Maria Nazareth Soares. Literaturas africanas de lingua portuguesa: percursos da memória e outros trânsitos. Belo Horizonte: Veredas \& Cenários, 2008.

FONSECA, Maria Nazareth Soares. Panorama das literaturas africanas de língua portuguesa. Cadernos CESPUC de Pesquisa, Belo Horizonte, n. 16, p. 13-69, set. 2007.

ISER, Wolfgang. A literatura e o leitor: textos de estética da recepção. Organização Luiz Costa Lima. Sao Paulo: Paz e Terra, 2002.

KRISTEVA, Júlia. Sol negro: depressão e melancolia. Tradução Carlota Gomes. Rio de Janeiro: Rocco, 1987.

LEAL, Luciana Brandão. Virgílio de Lemos: poesia em trânsito. 2018. $241 \mathrm{f}$. Orientadora: Maria Nazareth Soares Fonseca. Tese (Doutorado) - Pontifícia Universidade Católica de Minas Gerais, Belo Horizonte, 2018.

LEITE, Ana Mafalda. Poesia moçambicana, ecletismo de tendências. Poesia Sempre, Rio de Janeiro, n. 23, ano 13, p. 139-142, 2006.

LEITE, Ana Mafalda. Literaturas africanas e formulações pós-coloniais. Lisboa: Edições Colibri, 2013.

LEMOS, Virgílio de. Eroticus moçambicanus: breve antologia da poesia escrita em Moçambique (1944/1963). Rio de Janeiro: Nova Fronteira, 1999a. 
LEMOS, Virgílio de. Negra Azul: retratos antigos de Lourenço Marques de um poeta barroco (1944-1963). Maputo: Instituto Camões, Centro Cultural Português, 1999b.

LEMOS, Virgílio de. LEMOS, Virgílio de \& heterônimos: Bruno Reis, Duarte Galvão e Lee-Li Yang. Jogos de Prazer. Lisboa: Imprensa Nacional, Casa da Moeda, 2009.

PADILHA, Laura Cavalcante. Silêncios rompidos. In: PADILHA, Laura Cavalcante. Novos pactos, outras ficções: ensaios sobre literaturas afro-lusobrasileiras. Porto Alegre: EDIPUCRS, 2002. p. 171-186.

RIBEIRO, Margarida Calafate; MENESES, Maria Paula (org.). Moçambique: das palavras escritas. Porto: Edições Afrontamento, 2008.

SANTAELLA, Lúcia. Convergências: poesia concreta e tropicalismo. São Paulo: Nobel, 1986.

SANTILLI, Maria Aparecida; FLORY, Suely Fadul Villibor (org.). Literaturas de Língua Portuguesa: Marcos e Marcas. Moçambique por Tânia Macedo e Vera Maquêa. São Paulo: Arte \& Ciência, 2007.

SECCO, Carmen Lúcia Tindó. A magia das letras africanas: ensaios escolhidos sobre as literaturas de Angola e Moçambique e alguns outros diálogos. Rio de Janeiro: ABE Graph; Barroso Produções Editoriais, 2003.

SECCO, Carmen Lúcia Tindó. Afeto e poesia: ensaios e entrevistas; Angola e Moçambique. Rio de Janeiro: Oficina Raquel, 2014.

SECCO, Carmen Lúcia Tindó. Travessia e rotas das literaturas africanas de língua portuguesa (das profecias libertárias às distopias contemporâneas). Légua \& Meia, v. 1, n. 1, p. 91-113, 2002.

SENGHOR, Léopold Sedar. Liberté 1: Negritude et Humanisme. Paris: Éditions du Seuil, 1964.

SOUSA, Noémia de. Sangue Negro. Maputo: Associação dos Escritores Moçambicanos, 2001.

Submetido em 02 de junho de 2021

Aceito em 12 de outubro de 2021

Publicado em 30 de janeiro de 2022 